\title{
Compendio documental para el curso Pensamiento Sociopolítico de Simón Bolívar. Un aporte para el estudio de las ideas bolivarianas
}

\author{
Documentary compendium for the Sociopolitical Thought course by Simón \\ Bolívar. A contribution to the study of Bolivarian ideas
}

Recibido febrero 2021 Arbitrado marzo 2021 Aceptado abril 2021

Publicado mayo 2021

\section{Eliécer Hernández}

eliecerh81@gmail.com

Código ORCID: 0000-0002-0081-1685

Universidad Pedagógica Experimental Libertador. Miranda, Venezuela

\section{Resumen}

La finalidad del presente trabajo fue diseñar un compendio documental con el fin de brindar una herramienta para el abordaje del curso Pensamiento Sociopolítico de Simón Bolívar de la especialidad de Geografía e Historia del Instituto Pedagógico de Miranda "José Manuel Siso Martínez" de la UPEL. El estudio fue concebido con un diseño bibliográfico de tipo proyecto especial. El resultado de la investigación, materializado en la elaboración del material, permitió integrar los contenidos conceptuales, procedimentales y actitudinales con la finalidad de que los estudiantes cumplan con las actividades y por ende el logro de los objetivos. En fin, este material constituye un aporte novedoso y una herramienta científica para el estudio de la historia y, en especial, de las ideas bolivarianas de Simón Bolívar.

\footnotetext{
Abstract

The purpose of this work was to design a documentary compendium in order to provide a tool for approaching the Sociopolitical Thinking course by Simón Bolívar in the specialty of Geography and History of the Pedagogical Institute of Miranda "José Manuel Siso Martínez" of the UPEL. The study was conceived with a special project type bibliographic design. The result of the research, materialized in the preparation of the material, allowed the integration of the conceptual, procedural and attitudinal contents in order for the students to comply with the activities and therefore the achievement of the objectives. In short, this material constitutes a novel contribution and a scientific tool for the study of history and, especially, of the Bolivarian ideas of Simón Bolívar.
}

\author{
Palabras clave: \\ Compendio \\ documental; \\ pensamiento \\ sociopolítico; Simón \\ Bolívar
}

\section{Keywords: \\ Teaching; mathematics; planning; facilitation; evaluation}




\section{INTRODUCCIÓN}

$\mathrm{E}$ l estudio del pensamiento sociopolítico de El Libertador Simón Bolívar es un aspecto importante en la formación del estudiante de la Especialidad de Geografía e Historia. Hacer este estudio de manera profunda, requiere la revisión, no solo de la bibliografía especializada sino, de las fuentes primarias. El primer acercamiento del estudiante a la temática a estudiar, debe realizarlo a través de las fuentes bibliográficas, no obstante, son las fuentes primarias, y su revisión, a través de la crítica interna y externa, las que permiten la profundización del estudio, la posibilidad de una interpretación propia e incluso la creación de conocimiento pero, para ello es necesario que los estudiantes tengan la posibilidad cierta de acceder a estas fuentes bibliográficas y a los documentos.

Es en este orden de ideas que se propone, el abordaje de la temática del curso Pensamiento Sociopolítico del Libertador Simón Bolívar, a través de la elaboración de un compendio documental, producto de lo abordado en el programa del curso. Este material y la guía para su revisión a través de la crítica interna y externa, sería la materialización de esa posibilidad cierta de acceso a la fuente primaria.

El Discurso ante la Sociedad Patriótica, Manifiesto de Cartagena, Decreto de Guerra a Muerte, Manifiesto de Carúpano, Carta de Jamaica, Discurso de Angostura, Constitución de Bolivia, el Mensaje a la Convención de Ocaña y Congreso Anfictiónico de Panamá se convierten precisamente en los instrumentos de análisis de la propuesta y que tiene el propósito del acercamiento de los estudiantes a estas fuentes primarias, tal y como lo plantea la profesora Ruíz de Jerez (2004) sería:

Afianzar el espíritu de lectura, reflexión y análisis en nuestros estudiantes mediante el contacto con los escritos y documentos bolivarianos que le permita considerar acontecimientos pasados y su vigencia. A través de este tipo de razonamiento el estudiante podrá meditar sobre la importancia y aun vigencia de gran parte del Pensamiento Bolivariano. (p. 3)

El curso de Pensamiento Socio-Político de Simón Bolívar está inserto en el Diseño Curricular del año 1996, perteneciente al 
Bloque del Componente de Formación Especializada de tipo homologado obligatorio, con un nivel de integración y de modalidad a distancia. Con relación a este diseño, es menester tomar en consideración las bases que la Universidad utiliza para su desarrollo; en primer lugar la Universidad se planteó como fin, alcanzar las metas establecidas en el ordenamiento jurídico que ampara la Constitución Nacional de la República Bolivariana de Venezuela (1999) en cuanto a la formación de ciudadanos con valores y principios de solidaridad nacional, latinoamericana y mundial, expresado en el artículo $\mathrm{N}^{\circ}$ 1"La República Bolivariana de Venezuela es irrevocablemente libre e independiente y fundamenta su patrimonio moral y sus valores de libertad, igualdad, justicia y paz internacional en la doctrina de Simón Bolívar, El Libertador" (p. 1).

La segunda consideración viene dada en la necesidad de desarrollar en los ciudadanos la racionalidad y criticidad, con la finalidad de lograr la comprensión de los procesos históricos y el entendimiento de la realidad nacional. Ahora bien, el Diseño Curricular. Documento Base de la Universidad Pedagógica Experimental Libertador (UPEL, 1996) sustenta sus principios en la pertinencia y el compromiso social, el principio de la integridad, el principio de la modernización y por último el principio técnico curricular. De los cuatros se tomará el principio de la pertinencia y el compromiso social, a fin de darle forma y fundamentación a esta investigación.

Por otro lado, la organización curricular, responde a los principios y lineamientos de las Políticas de Formación Docente del Estado, las Políticas de Docencia de la UPEL, propósito del currículo y el perfil del egresado con la finalidad de conformar una estructura de cuatro componentes curriculares, según lo indica el diseño curricular (UPEL, 1996): "Formación General, Formación Pedagógica, Formación Especializada y Práctica Profesional, entendido los componentes como un conjunto de actividades y experiencias que se organizan de manera significativa en cursos, fases y actividades de extensión, que se distribuyen en dos bloques; el homologado y el institucional" (p. 14).

El componente de Formación Especializada se dirige a lograr la formación del futuro docente y la aplicación teórica y practica de un conjunto de conocimientos específicos necesarios para el desarrollo 
de habilidades y destrezas cognitivas, para el ejercicio docente en un nivel o modalidad del sistema educativo y en un área del conocimiento.

Con base a lo antes expuesto, surge la necesidad de incorporar un compendio documental para darle soporte teórico y metodológico al programa antes citado. En este sentido, el compendio documental es el resultado de una necesidad del Departamento de Geografía e Historia y de los alumnos que cursan la especialidad, y que a partir de entrevistas no estructuradas con los estudiantes de la especialidad de Geografía e Historia de la Extensión Río Chico se pudo evidenciar los siguientes aspectos:

1. La extensión de Río Chico cuenta con una biblioteca, pero en el caso de la especialidad no se dispone de fuentes bibliográficas ni documentales que permitan el abordaje del curso.

2. La gran mayoría de los estudiantes de la especialidad de Geografía e Historia habita en zonas rurales de la subregión de Barlovento, cuyas características fundamentales es la ausencia de bibliotecas y de cybers para llevar a cabo cualquier investigación de tipo histórica.

3. En las localidades circundantes a la Extensión Rio Chico no hay bibliotecas públicas y no se dispone de librerías para acceder a la adquisición de textos necesarios para cursar la especialidad.

4. En cuanto al área del departamento de Geografía e Historia del Instituto Pedagógico de Miranda "José Manuel Siso Martínez" se ha manifestado por intermedio de las Asambleas, la necesidad de actualizar los programas de los cursos, e incorporar estrategias didácticas novedosas y creadoras para la administración de los mismos.

A lo antes expuesto vale la pena agregar el señalamiento formulado por Rojas (2002), con el fin de refrendar las razones expresadas en líneas anteriores:

La praxis pedagógica durante el tiempo antes mencionado arrojó información sumamente valiosa acerca del rendimiento académico de los estudiantes, los cuales han manifestado la necesidad de un material didáctico el cual les facilite la comprensión de la historia patria... (p. 12) 
Estas observaciones permitieron formular la propuesta de un compendio documental para la administración del curso Pensamiento Socio-Político de Simón Bolívar, el cual se conformaría con los siguientes documentos:

1.- Discurso ante la Sociedad Patriótica

2.- Manifiesto de Cartagena

3.- Decreto de Guerra a Muerte

4.- Manifiesto de Carúpano

5.- Carta de Jamaica

6.- Discurso ante el Congreso Constituyente de Angostura

7.- Mensaje al Congreso Constituyente de Bolivia

8.- Mensaje a la Convención de Ocaña

9.- Discurso ante el Congreso Anfictiónico de Panamá

El aporte para el estudio del pensamiento bolivariano representa un mecanismo para la comprensión de la historia con una perspectiva crítica de los fenómenos históricos, tal como lo expresa Aguirre Rojas (2007):

La idea de ciencia conlleva necesariamente la de la existencia de todo un aparato categorial y conceptual específico, organizado de una determinada manera, a través de modelos y teorías de orden general, y que busca y recolecta dichos hechos y acontecimientos históricos para ensamblarlos e insertarlos dentro de explicaciones científicas comprehensivas. (p. 43)

Partiendo de lo anterior, la administración del curso de Pensamiento Sociopolítico de Simón Bolívar (PSB 0512) de la especialidad de Geografía Historia se propone:

Afianzar el espíritu de lectura, reflexión y análisis en nuestros estudiantes mediante el contacto con los escritos y documentos bolivarianos que le permita considerar acontecimientos pasados y su vigencia. A través de este tipo de razonamiento el estudiante podrá meditar sobre la importancia y aun vigencia de gran parte del Pensamiento Bolivariano. (Ruiz de Jérez, 2004, p. 3) 
De lo antes expuesto, se desprende la necesidad de este proyecto especial por cuanto el mundo en el año 2020 vive una pandemia generada por un virus identificado como COVID-19, que ha modificado ostensiblemente el modo de vida de todos los seres humanos, tal como lo expresa la UNESCO (2020)

La pandemia mundial ha expuesto de forma patente las vulnerabilidades y los desafíos que afronta la humanidad. Además, ha mostrado un claro panorama de las desigualdades existentes, y una imagen más clara aún de las medidas que debemos adoptar, entre las que destaca asegurar la educación de los más de 1500 millones de estudiantes cuyo aprendizaje se ha visto obstaculizado por el cierre de las escuelas. (p. 3)

Todo esto ha generado la búsqueda de alternativas para dar continuidad a la educación, sobre todo en estos momentos en los que una pandemia ha impactado al mundo $\mathrm{y}$, en especial a la educación en todos los niveles, resulta necesario valerse de la tecnología porque puede brindar la ayuda necesaria, tal como lo expresa Ligarretto (2020) "La actual situación de pandemia ha puesto sobre la mesa a la educación virtual como una oportunidad para que el sector educativo continúe operando" (s/p).

En tal sentido, las escuelas, los padres, representantes, alumnos y padres deben aunar esfuerzos para sobrellevar los cambios abruptos en la forma de manejar el hecho educativo, y hacer uso de la tecnología como apoyo en la prosecución de los estudios en todos los niveles y modalidades que conforman el sistema educativo mundial.

Esta propuesta centra su atención en el abordaje del pensamiento de El Libertador Simón Bolívar por intermedio de los objetivos indicados en el programa oficial del curso aprobado en el año 2004; y profundiza en el estudio del pensamiento de Bolívar a partir del análisis crítico de sus documentos.

\section{Objetivos de la investigación}

\section{Objetivo general}

Proponer un compendio documental para el curso pensamiento Socio-Político de Simón Bolívar correspondiente al plan de estudios 
de la especialidad de Geografía e Historia del Instituto Pedagógico de Miranda "José Manuel Siso Martínez"

\section{Objetivos específicos}

1. Determinar la necesidad de incorporar un compendio de documentos fundamentales para la administración del curso de Pensamiento Socio-Político de Simón Bolívar perteneciente al componente de formación especializada de pregrado correspondiente al plan de estudios de la especialidad de Geografía e Historia del Instituto Pedagógico de Miranda "José Manuel Siso Martínez".

2. Seleccionar los documentos fundamentales para la elaboración del compendio para la administración del curso de Pensamiento Socio-Político de Simón Bolívar perteneciente al componente de formación especializada de pregrado correspondiente al plan de estudios de la especialidad de Geografía e Historia del Instituto Pedagógico de Miranda "José Manuel Siso Martínez".

3. Elaborar un compendio documental para el curso Pensamiento Socio Político de El Libertador perteneciente al componente de formación especializada de pregrado correspondiente al plan de estudios de la especialidad de Geografía e Historia del Instituto Pedagógico de Miranda "José Manuel Siso Martínez"

\section{Compendio documental}

El compendio documental presentado por medio de este proyecto especial se comporta como un material didáctico tal como lo explica Rojas (2002) "es un sistema mediante el cual se analizan las necesidades y metas de la enseñanza y partir de ese análisis se seleccionan y desarrollan actividades y recursos para alcanzar esas metas..." (p. 11)

Para dar soporte a la investigación es necesario referir el planteamiento formulado por Matos Aray (2009) "el producto comunicativo (oral o escrito) que se elabora en un contexto institucional educativo, con fines específicos" (p. 3) tiene por rasgos distintivos los elementos siguientes: la intención, el destinatario y el origen; de manera que el compendio documental pueda satisfacer en su "proceso de elaboración, se presta especial cuidado a la selección, organización y secuencia del contenido; pues, estos aspectos inciden significativamente en el aprendizaje" (p. 5). 
De allí que el compendio documental responde al diseño curricular de la institución y los objetivos indicados en el programa aprobado y vigente del curso, para los alumnos de la especialidad de Geografía e Historia del Instituto Pedagógico de Miranda "José Manuel Siso Martínez", y así dar cumplimiento al perfil del egresado de la especialidad precitada.

Otro rasgo esencial del compendio documental es la intención con la cual se elabora y es atender al alumno en sus necesidades académicas, y en la posibilidad de interactuar con el material se produzca el desarrollo de habilidades necesarias en el campo de las ciencias sociales; tal es el caso, el manejo de la crítica interna y externa de los documentos como fuentes primarias para el abordaje del estudio de la historia.

\section{MÉTODO}

$\mathrm{D}$ e acuerdo con los objetivos planteados el trabajo de investigación por su contenido se inscribe en un diseño bibliográfico; el tipo de investigación fue un proyecto especial.

La investigación se ejecutó en tres fases a saber:

\section{Primera fase}

En esta fase se identificó la necesidad institucional y departamental de incorporar el compendio de documentos para la administración del curso Pensamiento Socio-Político de Simón Bolívar con carácter homologado obligatorio, perteneciente al Componente de Formación Especializada del pensum de estudio del año 1996.

En un segundo momento se realizó un diagnóstico de los materiales existentes en la extensión de Río Chico para determinar la necesidad de diseñar un compendio de documentos que sirva como recurso bibliográfico a todos los estudiantes de la Especialidad de Geografía e Historia. En un tercer momento se realizó una revisión del programa del curso para la elaboración del compendio de documentos. 


\section{Segunda fase}

En esta fase se describen y explican los métodos y las técnicas utilizadas para la elaboración del compendio de documentos; en un primer momento se procedió a la selección del material documental de acuerdo a los contenidos establecidos en el programa del curso, para luego y a través de un scanner e internet compilar toda la información e incorporar las actividades del estudiante de acuerdo a los objetivos conceptuales, procedimentales y actitudinales.

En cuanto a la metodología utilizada para la selección de las lecturas se tomó en cuenta los siguientes criterios:

1. Páginas de internet de reconocida moralidad y trayectoria científica.

2. De reconocidos autores quienes aportan de manera sólida argumentos teóricos

3. De fácil interpretación.

4. Que permita la comprensión de la continuidad histórica

En cuanto a los criterios metodológicos se trabajará con la periodificación tradicional que implica el estudio de la Historia de Venezuela a través de la Primera, Segunda y Tercera República y en función de lo anterior y para darle soporte que teorice la información se presenta una descripción histórica.

\section{Primera República}

Con el nombre de Primera República se conoce en la historiografía venezolana el período transcurrido entre el 19 de abril de 1810 y el 30 de julio de 1812. Este lapso como tal, se inicia en Caracas con el movimiento del 19 de abril de 1810, cuando el gobernador y capitán general Vicente Emparan y Orbe y otras autoridades españolas son derrocadas pacíficamente y sustituidas por una Junta Suprema de Gobierno que al comienzo se declaró "protectora de los derechos de Fernando VII" pero cuyos actos se orientaban al logro de la independencia absoluta de Venezuela.

De acuerdo con el programa del curso pensamiento SocioPolítico de Simón Bolívar se estudiará el documento Discurso ante la Sociedad Patriótica, por las siguientes razones: 
1. Corresponde al objetivo integrador $\mathrm{N}^{\circ} 2$ del programa del curso.

2. Es el primer documento que marca la aparición política de Simón Bolívar en el año 1811.

3. El documento fue tomado de la obra Escritos Fundamentales publicado por Monte Ávila Editores y la información digitalizada disponible en la página web de la Academia Nacional de la Historia.

4. El documento permite integrar los elementos políticos, económicos y sociales del pensamiento de Simón Bolívar presente en el programa del curso; de modo que el alumno pueda utilizar una herramienta metodológica llamada crítica interna y crítica externa.

\section{Segunda República}

Según algunos historiadores es el período que va desde agosto de 1812 hasta diciembre de 1814. A este lapso también se le ha dado el calificativo de "Guerra a Muerte", pero no es del todo exacto, pues la guerra a muerte que habían iniciado de los realistas a mediados de 1812, fue declarada oficialmente en junio de 1813 por el general Simón Bolívar y sólo fue definitivamente abolida en noviembre de 1820 mediante el Tratado de Regularización de la Guerra, aunque a partir de 1818 prácticamente habían cesado la ejecución de prisioneros.

Lo que sí es cierto es que la Guerra a Muerte alcanzó su apogeo durante la Segunda República. Este período se inicia con la liberación de Cumaná (3.8.1813), por las fuerzas del general Santiago Mariño, como culminación de la Campaña de Oriente, y con la entrada en Caracas, el 6 de agosto, del general Simón Bolívar a la cabeza de su ejército victorioso en la llamada Campaña Admirable.

De acuerdo al programa del curso pensamiento Socio-Político de Simón Bolívar se estudiará el documento Discurso ante la Sociedad Patriótica, por las siguientes razones:

1. Corresponde al objetivo integrador $\mathrm{N}^{\circ} 2$ del programa del curso.

2. Es el primer documento que marca la aparición política de Simón Bolívar en el año 1811. 
3. El documento fue tomado de la obra Escritos Fundamentales publicado por Monte Ávila Editores y la información digitalizada de la página web de la Academia Nacional de la Historia.

\section{Tercera República}

De acuerdo con la historiografía venezolana, es el período que comienza con la restauración de las instituciones republicanas en Guayana en 1817, después de su definitiva liberación por Simón Bolívar y termina en diciembre de 1819 con la creación de la República de la Gran Colombia por el propio Bolívar. Tal como señalábamos al comienzo, debe tenerse en cuenta que Tercera República (al igual que Primera y Segunda República) es una expresión moderna, que no usaban los contemporáneos de aquellos sucesos, aunque a veces se habla de la "segunda o tercera época de la República".

En cuanto a los aspectos teóricos que fundamentan el caudillismo, las clases sociales, se procedió a la selección de lectura de autores de reconocida trayectoria en la investigación histórica, en este sentido se procedió a incorporar de páginas de Internet artículos referido a el caudillismo como fenómeno social que implica el poder militar de un individuo sobre otro y que permitió definir los aspectos políticos de Venezuela, otro de los aspectos teóricos que se tomaron en cuanto fue el estudio de la dinámica social de la Venezuela Colonial con la finalidad de demostrar que la lucha de clase permitió la configuración de la realidad colonial.

En tal sentido la propuesta pretende:

1. Analizar a través de autores reconocidos la conceptualización del proceso de Independencia de Venezuela, con la finalidad de desmontar concepciones acerca de la problemática de estudio y crear nuevas formas pensamiento.

2. Profundizar en el estudio del pensamiento de Bolívar desmitificado a partir del análisis crítico de sus documentos.

3. Emitir juicios de valor acerca el abordaje de categorías de análisis históricos que permitirán comprender los problemas de carácter históricos, tales como República, clases sociales, caudillismo, esclavitud, latifundio. 


\section{Tercera fase}

En esta fase se procedió a la estructuración del contenido del material de apoyo bajo los criterios desarrollado anteriormente, con la finalidad de que el participante pueda consultar un basamento teórico como alternativa didáctica que le permita al mismo tiempo el abordaje de problemas históricos para así construir el conocimiento y generar en el estudiante la crítica y el cuestionamiento de concepciones históricas. Es necesario aclarar que el manual de lectura no representa la única alternativa en la construcción de conocimiento, sino más bien debe ser visto como una estrategia más de aprendizaje que permita el abordaje de problemas históricos como didáctica.

\section{Propuesta del compendio documental}

El compendio documental tiene el objetivo de brindar una herramienta para el abordaje del estudio del pensamiento sociopolítico de Simón Bolívar en la Especialidad de Geografía e Historia del Instituto Pedagógico de Miranda "José Manuel Siso Martínez".

El abordaje del ideario de El Libertador a partir de criterios novedosos implica poner en marcha estrategias de aprendizaje que permitan a los alumnos de la especialidad de Geografía e Historia adquirir herramientas científicas para el estudio de la historia. La práctica pedagógica como realidad educativa en la actualidad amerita la incorporación de nuevos enfoques del cómo abordar los problemas de carácter histórico y en su afán de cambiar las concepciones tradicionales e incorporar nuevas formas de pensamiento que desmonten las anteriores; razón por la cual, el compendio documental como un aporte para el estudio de las ideas bolivarianas.

\section{Fundamentación de la compilación}

El estudio del Pensamiento de Simón Bolívar requiere el manejo de herramientas metodológicas creadas por la ciencia histórica, tal es el caso de la crítica interna y la crítica externa, a los efectos de reconstruir los hechos con el mayor rigor científico posible. Es por ello que es primordial el manejo de fuentes primarias por parte de los estudiantes de la especialidad de Geografía e Historia del 
Instituto Pedagógico de Miranda "José Manuel Siso Martínez". Con base en lo antes expuesto, se procedió a hacer una selección de documentos digitalizados por la Academia Nacional de la Historia de Venezuela y la obra titulada "Escritos Fundamentales" publicada por Monte Ávila Editores en aras de contribuir en la formación profesional de los futuros docentes en el campo de las ciencias sociales con criterios científico metodológicos.

La selección documental corresponde al contenido programático del curso Pensamiento Socio-Político de Simón Bolívar código PSB0512 el cual abarca el período histórico desde el año 1783 año de nacimiento de El Libertador hasta el año 1830 cuando se produce su fallecimiento.

A la par de lo antes mencionado, cabe destacar que los motivos sustanciales de la propuesta obedecen a las limitaciones para llevar a cabo las actividades de investigación por parte de los estudiantes de la especialidad a nivel de pregrado en la extensión de Rio Chico; por cuanto los archivos y centros de documentación histórica se encuentran ubicados en la ciudad de Caracas; en tanto que la extensión de Río Chico está enclavada en la subregión de Barlovento y la distancia geográfica es una variable importante porque los estudiantes se les dificulta el traslado y llegar a tiempo a dichos centros cuyo horario de atención es limitado. Aunado a ello, está la condición que buena parte de la población que hace vida académica en la Extensión ya citada, habita en las zonas rurales donde se adolece de bibliotecas o centros de consulta por internet (cyber).

Con base en lo anterior, se añade la ausencia de colecciones documentales y centros de investigación histórica que faciliten el acceso a las fuentes primarias las cuales son la materia prima para el desarrollo de las competencias investigativas en el área de Historia, y el abordaje de determinados contenidos contemplados en el programa del curso.

\section{Introducción de la compilación}

El presente compendio documental tiene por finalidad ser una herramienta pedagógica, que cumpla con los contenidos curriculares establecidos en el programa oficial del curso Pensamiento SocioPolítico de Simón Bolívar código PSB-0512, con el propósito de ser un 
soporte para la administración del curso con especial énfasis en la extensión de Río Chico.

A su vez se pretende estimular el aprendizaje de herramientas científicas de la historia, ya que forma parte del perfil del egresado en el campo de las ciencias sociales, específicamente la especialidad de Geografía e Historia; en el caso actual se trata de la crítica interna y la crítica externa de documentos a partir de la obra de Topolsky (1976).

Los documentos de Simón Bolívar se seleccionaron en conformidad con el objetivo $\mathrm{N}^{\circ} 2$ del programa oficial del curso, tal es el caso: Discurso ante la Sociedad Patriótica, Manifiesto de Cartagena, Decreto de Guerra a Muerte, Manifiesto de Carúpano, Carta de Jamaica, Discurso ante el Congreso Constituyente de Angostura, Mensaje al Congreso Constituyente de Bolivia, Mensaje a la Convención de Ocaña, Discurso ante el Congreso Anfictiónico de Panamá.

La metodología para el manejo de los documentos de El Libertador Simón Bolívar, será la crítica interna y la crítica externa de documentos a partir de la obra de Topolsky del año 1976, que consiste en determinar la confiabilidad y la veracidad de los documentos mediante la aplicación de una serie de pasos indicados por el autor precitado.

\section{Objetivos}

- Analizar el pensamiento de la Ilustración como fuente del discurso bolivariano.

- Revisar el pensamiento socio-político de "El Libertador" a través de sus documentos, proclamas, cartas y discursos.

- Analizar de forma critica el pensamiento socio-político de Simón Bolívar en la actualidad.

\section{Objetivos Integradores o Amplificadores}

1. Determinar con precisión cuáles fuentes permiten configurar el proceso de formación doctrinaria de Simón Bolívar.

2. Explicar los aspectos sobresalientes del ideario político de Simón Bolívar en la orientación enunciada en el temario y de las notas resaltantes de su trayectoria histórica (1783-1830).

3. Deliberar con sentido crítico, el pensamiento constitucional y aspectos orgánicos de las constituciones propuestas por Bolívar. 
4. Enunciar las ideas centrales con respecto a la Unidad Hispanoamericana Post Colonial.

5. Establecer la vigencia del Pensamiento de Simón Bolívar.

Para lograr los objetivos integradores, el curso Pensamiento Político y Social de Simón Bolívar, se dispone a través de contenidos conceptuales, procedimentales y actitudinales para que el grupo se integre en un equipo de trabajo en el que cada uno pueda aportar:

1. El resultado de la revisión exhaustiva de fuentes hemerográficas, documentales y bibliográficos para el estudio de la temática general presentada. (El profesor del curso para cada encuentro asignara lecturas por equipos y deberán ser deliberadas entre los compañeros).

2. Un acopio de material de información de variada naturaleza que sirva de base para lecturas y formulación de reflexiones en los diversos aspectos del temario cuyo resultado será el desarrollo de un Foro.

3. La profundización de un aspecto concreto de los escritos de Bolívar para ser evaluados en forma escrita en lo que hemos denominado Facilitación.

\section{Contenidos}

\section{Primera Unidad: Formación Doctrinaria de Simón Bolívar}

(Fuentes fundamentales en su formación política-social).

\section{Conceptual}

1. Proceso político-social y económico de Venezuela 1783-1810.

2. (Infancia y adolescencia de Simón Bolívar).

3. Ideas e influencias de la antigüedad clásica greco-romana en el pensamiento político-social Bolivariano.

4. Ideología de América hispana al concluir el tiempo de la dominación española.

5. Enciclopedismo e Ilustración española. Influencias en la cultura y el pensamiento de Bolívar a partir de 1810. (John Locke, Monstequieu, Voltaire, Condillac, Rousseau, D’Alembert, entre otros). 


\section{Procedimental}

1. Determinar cómo fue el proceso de construcción que fundamenta el pensamiento ideológico de Simón Bolívar

\section{Actitudinal}

1. Valorar la importancia de las lecturas, viajes y roce social de Bolívar para el entendimiento de la Formación Doctrinaria

\section{Segunda Unidad: Ideario Político}

\section{Conceptual}

1. Formas de Estado y gobierno: Monarquía, Aristocracia, República, Absolutismo, Democracia, Dictadura, Tiranía. La alternabilidad.

2. Posición de Bolívar frente al sistema federal y el sistema centralista. Formas mixtas.

3. Evolución del discurso político-social de Simón Bolívar a través de sus documentos públicos: Discurso ante la Sociedad Patriótica, Manifiesto de Cartagena, Decreto de Guerra a Muerte, Carta de Jamaica, Discurso ante el Congreso Constituyente de Angostura, Mensaje al Congreso Constituyente de Bolivia, Mensaje a la Convención de Ocaña y Decretos dirigidos al establecimiento de la educación pública.

\section{Procedimental}

1. Análisis del Discurso original de Simón Bolívar.

\section{Actitudinal}

1. Valorar la importancia del estudio del pensamiento de Bolívar sobre la base de sus documentos originales.

\section{Tercera Unidad: Pensamiento Constitucional. Aspectos Orgánicos}

\section{Conceptual}

1. Fuentes jurídico-constitucional que engrosaron el pensamiento de Bolívar: Revolución Francesa, Derechos Universales del 
Hombre y del Ciudadano, el Código Napoleónico, Constitución de Estados Unidos, otros.

2. Constitución de Angostura y Constitución de Bolivia, aspectos fundamentales: División y equilibrio de los poderes públicos: Legislativo, Ejecutivo, Judicial, Moral y Electoral.

3. Igualdad político-social, condición de ciudadano activo y ciudadano pasivo, libertad individual, esclavitud, y vínculos entre la educación y lo público y privado de la sociedad y la república enunciados en 1819

\section{Procedimental}

1. Análisis de la evolución del pensamiento de Bolívar plasmado en el articulado de las Constituciones de 1819 y 1826.

\section{Actitudinal}

1. Emisión de juicios críticos ante la evolución del pensamiento político de Simón Bolívar.

\section{Cuarta Unidad: Unidad Hispanoamericana Post-Colonial}

\section{Conceptual}

1. Significado del Congreso de Panamá.

2. Bases históricas de la Santa Alianza y la Doctrina Monroe.

3. Pensamiento integracionista de Bolívar: ¿Hispanoamericanismo o Panamericanismo?

4. Posición política de Bolívar frente al equilibrio de poderes en el mundo.

\section{Procedimental}

1. Análisis de la importancia histórica del Congreso de Panamá.

2. Comparación del ideario hispanoamericano y Panamericano.

\section{Actitudinal}

1. Reconocer la importancia manifiesta por Bolívar ante el efecto de equilibrio de poderes en el Mundo. 


\section{Quinta Unidad: Vigencia del Pensamiento Bolivariano}

\section{Conceptual}

1. Ideario Bolivariano tiempo y vigencia y actualidad Bolivariana.

2. Mito y realidad Bolivariana contemporánea.

\section{Procedimental}

1. Discusión en torno a la razón y energía del pensamiento Bolivariano hoy.

\section{Actitudinal}

1. Valorar el es y el sentir del Ideario político de Bolívar.

\section{Estrategias didácticas sugeridas}

Para el logro de los contenidos del curso y propiciar la máxima participación de todos los alumnos se desarrollaran las siguientes técnicas: Facilitaciones, clases participativas, discusiones dirigidas, foro y ensayos.

En ese sentido, se accionaran las siguientes actividades:

- Asignación de lecturas y discusión de las mismas: se señalaran una serie de lecturas por unidad. Los alumnos deberán abordarlas a fin de reforzar sus soportes teóricos.

- Facilitación: con base a los contenidos de cada Unidad se preparan facilitaciones en las cuales los estudiantes deben demostrar dominio de contenido y de grupo.

- Elaboración de revista: los estudiantes darán continuidad a la revista huellas que desglosa información referida a los trabajos de campo, patrimonio histórico y fuentes documentales.

- Comprobación de lectura: El alumno a través de una prueba escrita demuestra el dominio de una lectura específica.

\section{Recursos}

Para lograr los objetivos propuestos se sugiere la utilización de los siguientes recursos:

- Documentos: como el caso de Boletines y Epistolarios.

- Bibliográficas teóricas: los que tratan sobre teoría de la Historia y la investigación histórica. 
- Bibliográficas específicas: las que abordan el tema de investigación en lo concreto.

- Bibliográficas generales: las que tratan el tema en forma general.

- Hemerográficas: todos los artículos de revista, folletos, hojas sueltas, impresos varios.

- Material didáctico: transparencias, mapas, otros.

\section{Evaluación de los aprendizajes}

Cumplida la fase anterior en todas sus partes, ya delimitado con precisión el contorno y alcance del tema, los alumnos participantes deben cumplir a cabalidad las siguientes actividades, correspondiente con las cinco unidades:

A. Facilitación. Que debe cumplir los siguientes aspectos:

* Presentar una síntesis de los acontecimientos históricos y de la acción pública del Libertador. Debe preocuparse por resaltar el contexto histórico en el cual se inserta la acción y pensamiento de Bolívar.

* Identificar claramente aquellos aspectos importantes en pertinencia con el contenido programático. El facilitador hará una breve síntesis de su contenido y dará la razón de su importancia para el estudio del tema. Debe utilizar recursos didácticos diversos (contribuyendo esto con la articulación que debe existir entre el curso y la formación pedagógica del estudiante) a fin de que al final del curso cada alumno posea una información completa de todos los aspectos presentados a través de esta estrategia. (Véase Anexo l).

* Al final de cada facilitación se debe cerrar, con un resumen y/o conclusión.

\section{B.Comprobación de lectura}

* Serán asignadas dos lecturas específicas destinadas a su interpretación y análisis individual. La comprobación de las mismas se realizará en fechas diferentes a través de un resumen escrito durante una clase determinada procediendo a informar a los alumnos con antelación su fecha de aplicación. 


\section{Revista}

* Durante el desarrollo del curso se programará un trabajo de campo. El resultado de la visita será a través de una revista.

\section{Actividades que debe realizar el alumno luego de finalizar la lectura de los documentos. Crítica externa e interna de documentos en base a la propuesta de Bello (2003)}

La crítica de fuentes documentales en el sentido estricto del término, podría definirse con mayor precisión sobre la base de la propuesta de la obra de Topolsky (1996) Introducción a la Metodología de la Historia que plantea las siguientes afirmaciones y modificado por el profesor Bello (2003).

1. La crítica de fuentes, tanto externa como interna, debe contestar a la pregunta: ¿Los datos proporcionados por una fuente concreta están de acuerdo con los hechos? Esto implica que salte a primer plano la cuestión de la fiabilidad del informante.

2. El primer paso en la crítica de una fuente consiste en investigar su autenticidad (crítica externa).

3. segundo paso en la crítica (esto atañe a las fuentes indirectas) de una fuente consiste en averiguar si el informante es fiable o no (crítica interna).

4. Para determinar la fiabilidad del informante, primero tenemos que examinar la autenticidad de la fuente; sin embargo, el estudio de esta autenticidad exige también, a veces, información sobre la fiabilidad del informante, o sea, sobre la veracidad de los datos que transmite.

Esto supone que el estudio de la fiabilidad de la información se considera como la meta principal de la crítica de fuentes, externa e interna, y que la crítica externa se identifica con el estudio de la autenticidad de las fuentes, y la crítica interna, con el estudio de la fiabilidad de la información.

Después de haber leído los documentos debe proceder a la aplicación de la crítica interna y externa de los mismos, bajo criterios bien definidos y con la ayuda de un esquema que a continuación se te presenta: 


\section{Crítica interna: estudio de la fiabilidad de las fuentes se aplicarán los siguientes pasos:}

1. Verificación de las instancias que emiten el documento: es sumamente importante verificar la fiabilidad del informante, si suele dar información verdadera.

1.1. Debe usted comprobar el ente emisor y la veracidad del documento ubicando el mismo en un momento histórico determinado, mediante la constatación de fuentes bibliográficas para dar certeza de la existencia del organismo e individuo que emite la fuente.

1.2. Examen de fiabilidad. Comprobar la existencia del ente emisor.

2. Medio de transmisión de la información.

2.1. Debe usted indicar el acceso primario de la fuente,

2.2. Conjunto de valores que posee el informante.

2.3. Ámbito socio político del destinatario y el receptor del documento

2.4. Intenciones del informante

3. La descripción del autor.

3.1. Rasgos característicos de la persona o institución que emite el documento

3.2. Comparación de esas características con descripciones de autores cuyos nombres son reconocidos.

4. Desciframiento.

4.1. Ubicar en el documento las características lingüísticas de la época.

\section{Crítica externa: de la autenticidad de las fuentes}

1. Fecha y lugar de origen.

1.1. La lectura de la información directa sobre el tiempo y el lugar de origen que establece la propia fuente.

1.2. La comprobación de la información obtenida (Lectura de boleo).

2. Examinar la propia historia del documento. Por qué y para qué se redactó.

2.2. Características socio políticas del ambiente histórico donde se da el documento. 
3. Las características externas de los documentos.

3.1. Analizar los puntos de vistas que no contiene y los que contiene (anacronismos).

4. Autenticidad del documento.

4.1. Establecer si la copia es original.4.2. Mencionar si es un extracto, copia, si es posible comparar con la original.

\section{Actividades complementarias}

1. Utilice la técnica del subrayado para ubicar en cada documento las categorías históricas presentes en el mismo.

2. Utilice un diccionario de Historia para consultar el significado de cada categoría histórica.

3. Elabore una ficha para cada categoría histórica, donde debe reflejar la bibliografía consultada y el significado de cada categoría.

4. Elabore un cuadro resumen para plasmar las ideas y/o proyectos presentes en cada documento de El Libertador.

5. Elabore un mapa mental donde se identifiquen los elementos principales del contexto para cada uno de los documentos.

\section{CONCLUSIONES}

A efectos de la administración de cada curso que ofrece el $\triangle$ IPM. "José Manuel Siso Martínez" a través del 1 Departamento de Geografía e Historia se hace necesario la elaboración de su respectivo programa ajustados a los lineamientos suministrados por la Sede Rectoral y en atención a las especificaciones dadas por la Unidad de Currículo. En el caso del curso que concierne al presente proyecto especial, está aprobado por la Unidad de Currículo en fecha 30 de enero de 2006.

El Departamento de Geografía e Historia consciente de la responsabilidad frente al estudiantado brinda un apoyo en su formación profesional, a través del compendio documental como material didáctico, con la finalidad de profundizar en el estudio del pensamiento bolivariano; cumpliendo así lo establecido en el programa elaborado por la profesora Yliana Ruíz de Jerez.

El compendio documental permitirá a los educandos acceder a las fuentes primarias representadas por los escritos de El Libertador Simón Bolívar, y al mismo tiempo adquirir herramientas 
científicas de la historia mediante la aplicación de la crítica interna y la crítica externa; a la par de ello, se convierte en un instrumento útil para los estudiantes y profesores que hacen vida en El Instituto Pedagógico de Miranda "José Manuel Siso Martínez".

Para la elaboración del compendio documental como material didáctico para la administración del curso Pensamiento SocioPolítico de Simón Bolívar para la especialidad de Geografía e Historia, es preciso señalar que los mismos se ajustan a los lineamientos emanados por el programa oficial del curso aprobado por la Unidad de Currículo.

La propuesta del compendio documental permitió integrar los contenidos conceptuales, procedimentales y actitudinales con la finalidad de que los estudiantes cumplan con las actividades y por ende el logro de los objetivos. En este sentido, el compendio documental se convierte en un instrumento didáctico que busca interesar al alumno en la construcción de nuevos conocimientos, que posibilitará la adquisición y manejo de herramientas científicas de la historia como lo es el caso de la crítica interna y la crítica externa.

En este contexto la elaboración del compendio documental sobre el ideario bolivariano, se inserta de manera apropiada con todo lo señalado anteriormente; ya que favorece el aprendizaje de herramientas científicas de la historia, el alumno tiene contacto con las fuentes primarias y él desarrolla su propio análisis de cada documento; trayendo consigo la construcción de un aprendizaje significativo.

\section{REFERENCIAS}

Aguirre Rojas, (2008). Antimanual del mal historiador: O cómo hacer hoy una buena historia crítica. Caracas: El perro y la rana

Bello, E. (2003). Compendio de lecturas para la administración del curso optativo de Historia de Venezuela para la educación integral del I.P.M.J.S.M. (trabajo de ascenso). Universidad Pedagógica Experimental Libertador, Instituto Pedagógico de Miranda "José Manuel Siso Martínez", Caracas

Constitución Nacional de la República Bolivariana de Venezuela. (1999). Gaceta Oficial de la República Bolivariana de Venezuela, 35453, marzo 3, 2000 
Ligarretto, R. E. (2020). Educación virtual: Realidad o ficción en tiempos de pandemia. Recuperado de https://www.javeriana. edu.co/ pesquisa/educacion-virtual-realidad-o-ficcion-en-tiemposde-pandemia/

Matos Aray, M. (2009). Producción de materiales impresos a partir de propiedades textuales e instruccionales. Recuperado de http://biblo.una.edu.ve/ojs/index.php/UNAINV/article/view/734/ 707

Ruíz de Jerez, Y. (2004). Programa del curso Pensamiento SocioPolítico de Simón Bolívar. Caracas: UPEL

Topolsky, J. (1976). Metodología de la Historia. Serie Mayor

UNESCO (2020). La educación en un mundo tras la COVID: Nueve ideas para la acción pública. Recuperado de https://unesdoc.unesco.org/ark:/48223/pf0000373717_spa?fbclid =IwAR0e5c-VoMjNLZPzE17lrcLjgV66zg1pgrP9sBObB̄̄EToy GCA5zO2s MShGE

Universidad Pedagógica Experimental Libertador. (1996). Diseño Curricular, Documento Base. Vicerrectorado de Docencia, Caracas 